\title{
Empowerment of Women through Self-Reliance Approach in the Rice Processing Village Programme
}

\author{
C.A.K. Dissanayake* ${ }^{*}$ J.A.S. De Silva ${ }^{1}$, W.M.C.B. Wasala ${ }^{2}$ and \\ B.M.K.S. Thilakarathne ${ }^{2}$
}

Postgraduate Institute of Agriculture

University of Peradeniya

Sri Lanka

\begin{abstract}
Paddy farming is a direct source of income for the rural farmers in Sri Lanka. However, the middlemen involved in the rice supply chain reduce the farmer's profit from paddy while increasing the market price of rice for consumers. The Rice Processing Village programme (RPV) was introduced by the Institute of Post Harvest Technology (IPTH) of Sri Lanka in 2005, as a self reliant venture under which farmers parboil and process paddy into rice and other rice-based products. This venture leads to a high income for the farmer and low price for the consumer. One of the main beneficiary groups of the $R P V$ programme was housewives of the farming communities. This paper aims to determine the effect of the RPV programme on empowerment of women with respect to their human, social, and economic capital. A total sample of 150 members including 110 women and 40 men were randomly selected from 30 RPVs in the North Central Province of Sri Lanka. Data were collected through a field survey using a questionnaire, key informant interviews, observations and secondary data sources. The study revealed that the women members have improved their social contacts with fellow farmers and stakeholder organizations, learnt to use resources efficiently, and developed their knowledge, skills and attitudes to become a productive workforce in the rural economy. The RPV programme has helped them to use their free time in generating an additional monthly income of Rs. 6,463 per family. Therefore, it can be concluded that the RPV programme had empowered the women members in their human, social and economic aspects in these villages.
\end{abstract}

Keywords: Empowerment, rice processing village, self reliance approach, women

\section{INTRODUCTION}

Women in Sri Lanka play a significant role in all development spheres, and their contribution to the national economy is enormous (Department of Census and Statistics, 2013). But most of the family's income is earned by the male counterpart. Overall, women spend more time on reproductive activities like child bearing and rearing responsibilities, and domestic tasks, required to guarantee the maintenance and reproduction of the labour force in the global perspective. While engaging in reproductive activities, rural women have traditionally played, and continue to play an important role in both rice production and postharvest activities including transplanting, weeding, harvesting, carrying loads and storage of grains. Furthermore, parboiling of paddy is exclusively considered as women's work (FAO, 2013).

\footnotetext{
Department of Agricultural Extension, Faculty of Agriculture, University of Peradeniya, Sri Lanka

Institute of Postharvest Technology, Jayanthi Mawatha, Anuradhapura, Sri Lanka

Corresponding author: chamdissanayake@yahoo.com
} 
However many areas of economic activities which women participate go unseen and or unvalued.

Many countries have focused on empowerment of women, as it will fuel the economic development of a country (Sunfo, 2013). Sri Lanka also has launched many development activities aimed towards empowering women. Many governmental and non-governmental organizations are aiding empowerment through supporting women in starting and developing self-reliant ventures. According to Carter (2012), self-reliance is defined in three facets; knowing that people can solve a problem for themselves, ensuring that they have the resources and skills to do something about it, and granting them freedom from external obstacles. According to Ojameruaye (2004), the self-reliant development is defined as that type of development, which relies on their own human and material resources or a do-ityourself approach. This approach is widely used in developing countries to eliminate many socioeconomic problems including poverty, unemployment, and inequity.

Paddy, being the major agricultural crop cultivated, plays a major role in Sri Lankan economy. In 2012, the paddy production was 3.846 million metric tons (Central Bank, 2013). Paddy farming is a direct source of income for the rural farmers as well as an indirect source of income for many including the providers of support services, paddy millers and traders of paddy and rice (Kumara, et al., 2008). However, due to high cost of production, lower prices at the harvesting season and debt to be paid just after harvesting, especially small-scale paddy farmers in Sri Lanka have to face many challenges. Furthermore, generally smallscale paddy farmers are used to sell their unprocessed paddy either to middlemen or to the millers, rather than adding value by themselves. Therefore, in between the paddy farmers and the consumers, there are number of middlemen involved, resulting a longer supply chain, thus the share of the consumer rupees that goes to the farmer declines. By shortening the supply chain, consumers can get high quality rice at a reasonable price (Gamawelagedara, et al., 2010) while ensuring a reasonable return to the producers.

The Institute of Post Harvest Technology (IPHT) introduced the rural level rice parboiling and processing enterprises to the farming communities through the Rice Processing Village (RPV) programme started in 2005. The programme was scaled up in the major paddy cultivated districts in the country including Polonnaruwa, Kurunegala, Ampara, Kandy and Puttlam. The RPV programme attempts to increase the income level of the paddy farmers through selling rice instead of paddy, initiate agro-based self-employment opportunities at rural level (parboiling and processing), develop small/medium scale rice mills to produce high quality rice at rural level, and make high quality rice available at a lower price to the consumers (IPHT, 2006). Farm women have been a major group of beneficiaries of this programme. However, the impact of the RPV programme on empowerment of rural women of the farming families has never been studied. Therefore, this paper attempts to evaluate the effectiveness of the RPV programme in empowering women through this self-reliance approach. Special emphasis was given to the development of human capital, economic and socio-cultural aspects of the women participated in the programme.

\section{METHODOLOGY}

The North Central province is one of the major paddy producing area in the country, where the RPV programme was launched by the IPHT in 2005. Thirty villages from 10 Divisional Secretary divisions of Anuradhapura and Polonnaruwa districts were randomly selected for this study conducted during the period from 2011 to 2012. 
Out of the 563 members who initiated rice processing activities in these 30 RPVs, 150 members $(27 \%)$ consisting 40 men and 110 women were selected randomly on proportional basis. Further from same study area a control sample of 30 including both men and women were also randomly selected for the study. Both quantitative and qualitative data were gathered through a field survey using a pre-tested semi-structured questionnaire. Furthermore, data were collected from key informant interviews with, elderly men and women in the farming communities of these villages, Agricultural Instructors of the Department of Agriculture, Agriculture Research and Production Assistants, relevant officers of the IPHT and the organization involved in funding these RPVs. The presidents of the Rice Processors' Associations (RPA) in each village were also interviewed. Information was also taken from direct observations and secondary sources. Data were analyzed using the Minitab statistical package.

\section{RESULTS AND DISCUSSION}

The RPV programme was introduced as an income generating venture using a self-reliance approach to develop the livelihood of the rural community. The main categories of the beneficiaries of this programme had been paddy farmers, farm women, self-employment seekers and other interested groups who intend to gain an extra income. Farm women had been a major focus in this programme. Of the total beneficiaries $74 \%$ had been women members.

All the beneficiaries used $100 \%$ family labour in the RPV programme. Out of the total labour input in rice processing activity, $76 \%$ was from women. Even if the membership of the Rice Processors' Association (RPA) was taken by a male member of the family, the rice processing activities done at their household was entrusted to the women in the family. Furthermore all respondents including women agreed to the fact that parboiling is a work done by females. All respondents undertook the rice processing by parboiling within their household premises. The respondents at their first year of operation had processed an average amount of $2016 \mathrm{~kg}$ of paddy per household per month, which increased up to 3532 $\mathrm{kg}$ of paddy after an average of five years. At the initial stage, the average contribution of own paddy to the total paddy processed was $80 \%$, which reduced to $60 \%$ after five years along with their increased processing capacities. All (100\%) respondents, both men and women claimed that, thanks to this programme they do not need to look for employment in other places. Traditionally and as reported in the interviews, husbands do not want to send out their wives to engage in extra domestic income generating activities, since it can lead to social problems. Rice processing enabled women to engage in income generating activity at home while doing their other household chores. Therefore, all respondents reported that this rice processing activity provided a new pathway for women to open up into the income earning facet of life. The following section discusses the women empowerment with respect to human capital, economic and socio-cultural development.

\section{a). Human capital development}

According to the IPHT, human capital development has been an essential component in this RPV programme because it requires special knowledge and skills to use the newly 
introduced parboiling technique ${ }^{3}$. Furthermore, attitude change was also required to use the new technique of parboiling for income generation, which was only for self-consumption earlier. Therefore, at the initial point the villagers were made aware of the programme and a complete training programme on high quality rice processing at rural level was conducted by IPHT. The majority (75\%) who participated in this training had been women. This could be due to the fact that the training programme was held in the mornings and men were too busy to attend. Furthermore, parboiling is usually done and believed to be a women's task. All the participants were using the traditional method of parboiling before attending the training programme.

The training imparted knowledge, skills and attitudes on improved high quality paddy parboiling techniques. All the beneficiaries who had participated in the survey claimed that their knowledge had been improved by the training given. After making the trainees aware of the technique, practical demonstrations were conducted and hands-on experience was given to enhance the skills of parboiling with the new technique. The observations revealed that respondents practice the new improved technology in the correct way indicating the skill development received through the training.

In order to achieve high profits and self-reliance, the participants were expected to adopt the technology as an income generating activity. According to the respondents, the cost benefit analysis included in the training, the demonstrations, and the easiness of the new practice compared to the traditional method favoured the change of their attitudes towards the adoption of the new technique as an income generating activity. The supervision and follow up activities conducted filled the knowledge, skills and attitude gaps of the participants on this activity. Furthermore, the involvement in this rice processing activity had facilitated $72 \%$ of women to receive extra training and fill their knowledge gaps on other relevant subject matters such as grain storage and preparation of rice based value added products. All respondents, including both women and men claimed that this venture had put the women in their villages at ease in parboiling, which was earlier considered as a very strenuous activity. The majority of women respondents $(91 \%)$ indicated that because of the new livelihood and income earned, they feel mentally strong, gained self-confidence, and lost the fear of getting exposed and being socially mobilized. All the women respondents said now they feel economically independent. All these factors show that this programme had a favourable impact on the human capital development of the women participants.

\section{b). Economic development}

The RPV program has focussed on enabling the participants to start a self - reliant business and gain a higher profit from paddy cultivation. The sample consisted of members who had initiated the rice processing venture two to seven years prior to the study. The total percentage of participants continuing the rice processing activity for sale at the time of the study was $56 \%$, of which $68 \%$ were women. About $7 \%$ ( $70 \%$ women) of them had permanently discontinued their new venture due to various personal reasons.

With the new rice processing venture, the members earned an average net profit of Rs.10.00 per kilogram of rice with the assumptions of price of paddy Rs. 30.00, sale price of rice

\footnotetext{
${ }^{3}$ The traditional paddy parboiling technique involved direct boiling of paddy by adding paddy and water together into a pot and heating it until paddy is parboiled. This exerts many unfavourable traits in rice such as high chalky, broken, and discoloured grains. It is also a high time, fuel and labour consuming activity. The new technique eliminates all these drawbacks by prior soaking and use of steam to parboil paddy which produces high quality rice.
} 
Rs.60.00 and rice yield 68\%. (Detailed cost benefit analysis is given in Dissanayake et. al. (2012).

It was revealed that the women beneficiaries earn a mean income of Rs. 6463 per month (ranging between Rs. 3,500 to Rs. 50,000) by selling rice instead of paddy. The average income earned by the male counterparts' amounts to Rs. 9,845 (ranging between Rs. 3,500 to Rs. 39,000). Table 1 shows the contribution from income gained through rice processing to the member's total income as well to the total family income of men and women separately. It reveals that $60 \%$ of women were depending totally on rice processing as the sole income for herself while all men were having at least one other income source apart from rice processing. This indicates that the majority of women participants who were not earning any income had found a livelihood through the RPV programme. Further, for $92 \%$ of the women the income from rice processing was their major income source (contributing to more than $50 \%$ of their income). This was very high compared to the $50 \%$ of men whose rice processing income was the major income source $\left(\chi^{2}-46.477 ; p-0.000\right)$. Further when compared with the income earned by the women in the control sample, the income earned by women members of this rice processing venture showed significantly higher income $(t=2.91$; $\mathrm{p}=0.002$ ). This clearly reveals the favourable impact on the economic development of the women participants of this RPV programme.

Table 1. Percentage of income earned from rice processing, from member's income and total family income

\begin{tabular}{ccccc}
\hline $\begin{array}{c}\text { Category of income } \\
(\%)\end{array}$ & \multicolumn{2}{c}{ From member's income (\%) } & \multicolumn{2}{c}{ From total family income (\%) } \\
\cline { 2 - 5 } & Women & Men & Women & Men \\
\hline $\mathbf{1 0 0}$ & 60 & 0 & 0 & 0 \\
$\mathbf{7 5 - 9 9}$ & 13 & 22 & 4 & 11 \\
$\mathbf{5 0 - 7 4}$ & 19 & 28 & 13 & 17 \\
$\mathbf{2 5 - 4 9}$ & 8 & 11 & 30 & 22 \\
$\mathbf{0 - 2 4}$ & 0 & 39 & 53 & 50 \\
\hline
\end{tabular}

These respondents were having an average number of four (04) members in the family which ranged from one to seven. All women participants (100\%) claimed that with this RPV programme, they have enough money to cover up their own expenses such as contribute more for village development activities such as donations for charity work, engage in spiritual activities such as almsgiving and going on pilgrimage. All women claimed that earlier they had to ask for money from the income earning other family members when they need. But now they are economically independent and have the freedom to spend on anything they want. Some women respondents $(2 \%)$ indicated that they sometimes purchase paddy from their husbands for the rice processing activity.

In addition to the income, these women respondents had accumulated many assets such as infrastructure developments for this rice processing activity. With the programme, all participants have acquired the improved parboiling vessels introduced by the IPHT. At the initial stage, they purchased only one parboiling equipment and at the time of the study $16 \%$ of the women participants had two or more vessels. 


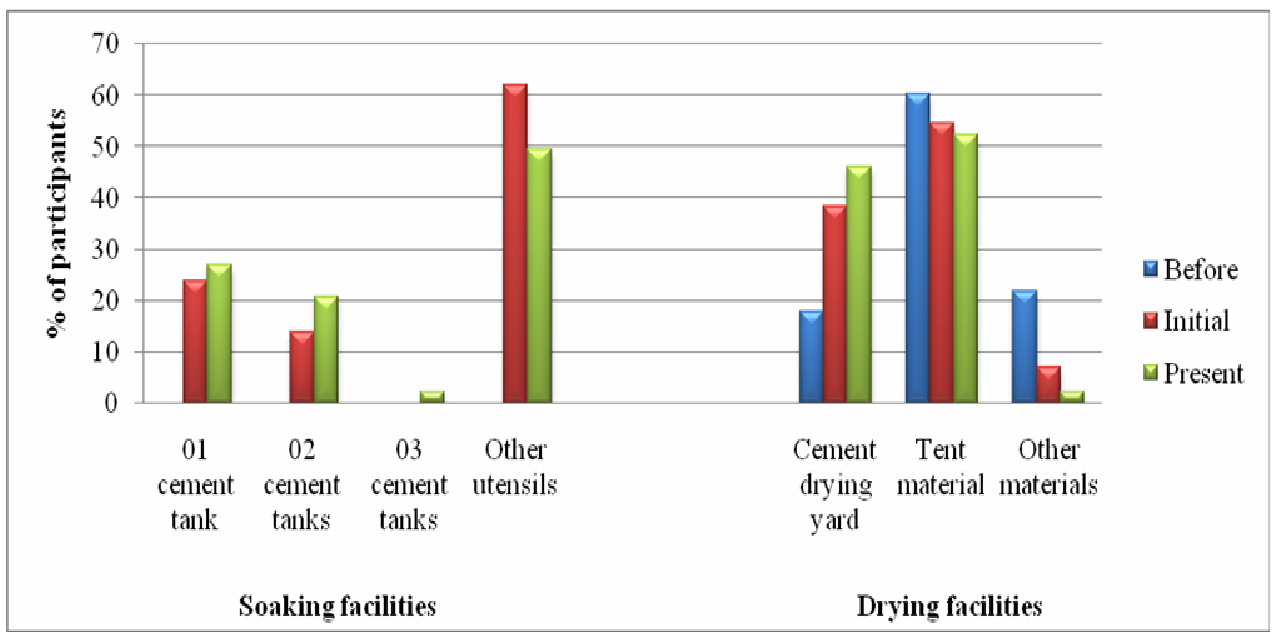

Fig. 1. Infrastructure used for paddy processing

Note: Other utensils under soaking facilities include saucepans, barrels, basins, pots and buckets; other materials under drying facilities include bags and mats.

Pre-soaking had not been practiced by any of the participants before the programme. With the inception of this programme all had adopted the soaking practice and the details on facilities developed are given in Fig.1. It also indicates the usage of cement drying yards for drying of paddy. Cement drying yards and soaking tanks were the recommended practices by the IPHT.

Access to a rice mill and other facilities available for these women respondents were also studied. Fig. 2 describes the change seen before the RPV programme, at initial stage and at the time of the study of the programme. The ownership pattern and the access to destoning facility were observed as the major limitation in the rural level rice mills are shown in the Fig. 2. More number of women have moved towards obtaining destoning facilities and own rice mills. All women claimed that now they are able to work in rice mills where earlier it was considered suitable only for men and women were not physically strong enough to work in such situations. 


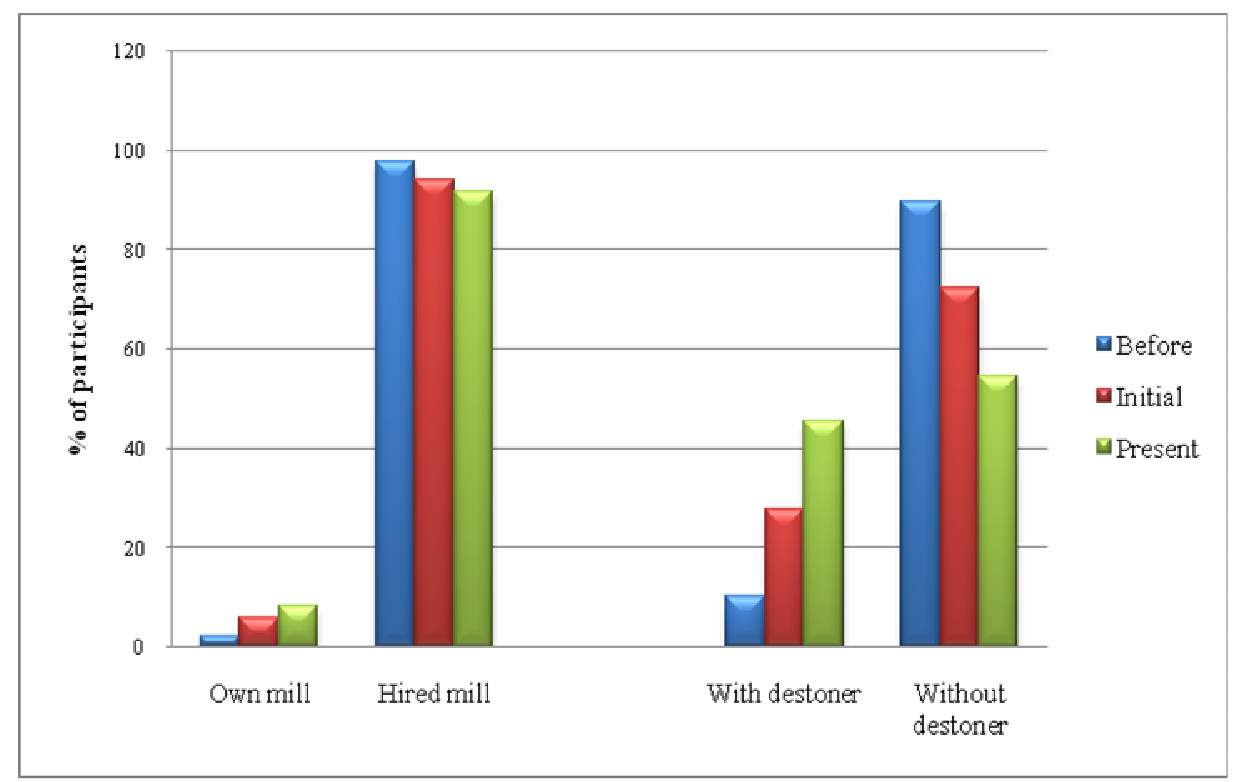

Fig. 2. Access to mills and destoning facility

Furthermore, these women participants had acquired other assets worth of Rs. 26,227 on average and ranging between Rs. 700 to Rs. 478,000. These assets include machines and building constructions for rice mills (9\% of women), construction and renovation of soaking tanks (56\% of women), drying yards (51\% of women) and paddy stores (11\% of women) which were directly having an impact on the rice processing activity. Apart from those, with the earnings from this RPV programme, these women participants had renovated their houses (39\% of women), bought household furniture and appliances like refrigerators, rice cookers, and gas cookers ( $89 \%$ of women).

Thirty nine percent of the women respondents have obtained credit to improve their rice processing activities. The findings revealed that the total amount of credit taken was not significantly different in women compared to their male counterparts $(t=-0.38 ; \mathrm{p}=0.709)$ indicating equality in obtaining credit (Table 2). Furthermore, $78 \%$ of women participants said that previously they were very reluctant to obtain credit and that their fear disappeared with this programme.

Table 2. Total amount of credit obtained and number of times

\begin{tabular}{lcccc}
\hline & \multicolumn{2}{c}{ Amount (Rs.) } & \multicolumn{2}{c}{ No. of times } \\
\hline Member & Women & Men & Women & Men \\
\hline Mean & $99,088.00$ & $110,615.00$ & 2.08 & 1.62 \\
\hline Mode & $30,000.00$ & $30,000.00$ & 1 & 1 \\
\hline Range & $30,000.00-380,000.00$ & $30,000.00-$ & $1-6$ & $1-3$ \\
& & $480,000.00$ & & \\
\hline
\end{tabular}




\section{C). Socio-cultural development}

Other than human capital and economic development, socio-cultural aspects have also been developed through the RPV programme. According to the key informant interviews, the women in general in these villages were staying in their houses supporting their husbands to do their farming activities. Earlier they were expected to do all the household chores and take care of the children and the family. They were not expected to earn an income. They were expected to be dependent on their husband's earnings. But, with the RPV programme, these aspects have changed. With this programme $78 \%$ of women participants indicated that their status in the society had improved. The women who had improved the status said that it is because of earning an income. Although earlier they had been helping with the husband's work to earn the income to the family, the women contribution was not visible and not accounted. But now they have a visible effect on the family income. About $43 \%$ of the women respondents claimed that they now feel more independent. Furthermore, $82 \%$ said that the family ties also have improved due to the programme and $90 \%$ of the men accepted it. This attributed to family members working together and need of mutual support to make the rice processing business a success.

After the IPHT training, the interested participants were collectivized into a Rice Processors' Association (RPA). Out of the 30 villages studied, 28 villages (93\%) had these 'RPAs. In these associations, $76 \%$ of the office bearers were women. The study revealed that the main function of this society is to strengthen and support the participants in achieving success in the rice processing activity. The RPAs facilitate purchasing paddy, selling rice, identifying market opportunities and improving bargaining power. It has also supported obtaining credit from local banks, and subsidies and other benefits from the supporting organizations. All $(100 \%)$ women respondents in the RPAs stated that with the grouping they are more empowered and socially mobilized as well as feel mentally and physically strong in carrying out rice processing activities. These women $(73 \%)$ have also gained more recognition in the village and had got involved more in the village level social activities such as shramadana and religious activities. They have also obtained membership in other village level societies in addition to the RPAs and become their office bearers.

Of the total participants, $94 \%$ of women and $97 \%$ of men admitted that their social contacts have improved through this programme. The respondents claimed that their contacts and linkages with fellow farmers and stakeholder organizations such as IPHT, local banks, other supporting organizations such as Department of Agriculture, Samurdhi Authority and NGOs were improved through this RPV programme. These social contacts have benefited in many activities in the programme, including obtaining credit facilities for the rice processing activities (Table 2).

\section{CONCLUSIONS AND RECOMMENDATIONS}

According to the findings, the self-reliance approach used in the Rice Processing Village programme has positively contributed to the empowerment of women through human capital, economic and socio-cultural development.

Since the programme seems sucessful in empowering women, it should be scaled up to reach the other paddy cultivating areas in the country as well. Special emphasis could be given to marginalized women, women in the war affected north and eastern areas and to the widowed women in paddy cultivating areas. 


\section{REFERENCES}

Carter, J. (2012). Reaching self reliance in development projects. Aid Effectiveness, Community Development, Ethics in development [Online]. [Accessed on 02.07.2013]. Available at www.whydev.org/self-reliance-in-community-development-projects-a-m

Central Bank of Sri Lanka. (2013). Annual report 2012. Central Bank of Sri Lanka, Colombo.

Department of Census and Statistics. (2013). [Online]. [Accessed on 02.06.2013]. Available at www.statistics.gov.lk/PopHouSat/Pop_Chra.asp

Dissanayake, C.A.K., De Silva,S., Wasala, W.M.C.B., Thilakarathne, B.M.K.S. (2012). An investigation of rice processing village programme. Tropical Agricultural Research. 24 (1).

FAO (Food and Agriculture Organization). (2013). Asia's women in agriculture, environment and rural production. [Online]. [Accessed on 15.10.2013]. Available at www.fao.org/sd/wpdirect/wpre0112.html

Gamawelagedara,W.C., Wickramasinghe,Y.M. and Dissanayake,C.A.K. (2011). Impact of rice processing villages on house hold income of rural farmers in Anuradhapura district. The Journal of Agricultural Sciences. 6, 91-98.

IPHT (Institute of Post Harvest Technology). (2006). Annual Report 2005. Institute of Post Harvest Technology, Anuradhapura.

Kumara, S.K., Weerakkody,P.R., Epasinghe,S., Epakanda,N.S.B. (2008). Viability of rice processing at house hold level. Hector Kobbekaduwa Agrarian Research and Training Institute. Colombo 07.

Ojameruaye, E.O. (2004). Strategies for self-reliant economic development of Urhoboland. [Online]. [Accessed on 02.07.2013]. Available at www.waado.org/geography/development/ojameruaye_strategies.html

Sunfo, United Nations Friendship Organization. (2013). [Online]. Accessed on 24.06.2013]. Available at sunfosrilanka.org/index.php/women-empowerment 